\title{
LETTERS AND CORRESPONDENCE
}

Letters and correspondence submitted for possible publication must be identified as such. Text length must not exceed 500 words and five bibliographic references. A single concise figure or table may be included if it is essential to support the communication. Letters not typed double-spaced will not be considered for publication. Letters not meeting these specifications will not be returned to authors. Letters to the Editor are utilized to communicate a single novel observation or finding. Correspondence is to be used to supplement or constructively comment on the contents of a publication in the journal and cannot exceed the restrictions for Letters to the Editor. The Editor reserves the right to shorten text, delete objectional comments, and make other changes to comply with the style of the journal. Permission for publication must be appended as a postscript. Submissions must be sent to Jay Umbreit, MD, PhD, Editor of Brief Reports/Letters to Editors, American Journal of Hematology, Winship Cancer Institute, Emory University, 1365-B Clifton Road, Suite B4100, Atlanta, GA 30322 to permit rapid consideration for publication.

\section{Low-Dose Local Palliative Radiotherapy in Newly Diagnosed Chronic Lymphocytic Leukemia}

To the Editor: Indolent non-Hodgkin lymphoma (INHL) and chronic lymphocytic leukemia (CLL) are very sensitive to radiotherapy (RT); unfortunately, no curative treatment is available. Patients with INHL and CLL may occasionally develop localized lesions, giving rise to distressing symptoms. It is well known that limited field conventional doses ( $\geq 20 \mathrm{~Gy}$ ) have traditionally been used, with good palliative results. However, a few studies had shown high response rates with low-dose (4 Gy) limited-field RT in recurrent, chemotherapy-refractory advanced INHL and CLL [1-5].

A 58-year-old woman presented with an $8 \times 9 \mathrm{~cm}$, mobile, painful, left submandibular mass. Systemic screening revealed no other abnormality. At the time of admission, the laboratory results were as follows: hematocrit, $36 \%$; white blood cell count, $30 \times 10^{9} / \mathrm{L}(18 \%$ neutrophils, $82 \%$ lymphocytes); and platelets, $156 \times 10^{9} / \mathrm{L}$. Peripheral blood smear revealed frequent mature appearing lymphocytes $(80 \%)$ and smudge cells without other abnormalities. Bone-marrow aspirate and trephine biopsy showed a hypercellular marrow with diffuse mature appearing lymphocyte infiltration. On flow cytometry, B lymphocytes showed dual positivity with $\mathrm{CD} 5$ and $\mathrm{CD} 19$, and also with CD5 and CD23. Rai stage I CLL was diagnosed by these findings.

Treatment consisted of radiotherapy (RT), 2 Gy $\times 2$ (total dose 4 Gy), given during 2 days with an $18-\mathrm{MeV}$ linear accelerator. Onset of response was clinically determined 1 week later, and total disappearance of the mass was established 2 weeks later. After completion of radiotherapy, the patient has been followed with Rai stage 0 CLL for 6 months. In CLL, the most frequently used form of RT is splenic irradiation. Irradiation of large, bulky lymphoid masses localized in one region, nonresponsive to chemotherapy, is also possible. In INHL, low-dose $(2 \times 2 \mathrm{~Gy})$ involved field radiotherapy (LD-IF-RT) has been reported in several studies. In 109 patients with an overall response rate of $92 \%$, complete response of $61 \%$, partial response of $31 \%$, stable disease of $6 \%$, and progressive disease of $2 \%$ were reported [1]. In a study of 48 patients with a median follow-up of 3.3 years, an $89 \%$ response rate was reported [2]. In a different study, complete remission was seen in $37 \%$ [3]. Two smaller series confirmed these results $[4,5]$. Of these studies, those of Haas et al. and Girinsky et al. did not include CLL patients, while those of Sawyer and Timothy and of Johannsson et al. included only $2(n=11)$ and $7(n=22)$ CLL patients, respectively. Johannsson et al. reported that patients with INHL had an overall response rate (RR) of $87 \%(74 \% \mathrm{CR}, 13 \% \mathrm{PR})$ and patients with CLL had an overall RR of $71 \%(29 \%$ CR, $42 \%$ PR) [5]. The results of the Johannsson study would seem to indicate that patients with CLL are slightly less likely to achieve an objective response than are patients with INHL and that responses are more likely to be partial than complete.

Low-dose RT is a highly effective and safe palliative treatment of localized mass in previously untreated patients with CLL. With this less aggressive therapy, patients with incurable disease have less toxicity and more improvement of the quality of life.

\section{H. Cuneyt Ulutin ${ }^{1}$ KURSAD KAPTAN ${ }^{2}$ Cengiz Beyan ${ }^{2}$}

${ }^{1}$ Department of Radiation Oncology, GATA, Etlik, Ankara, Turkey

${ }^{2}$ Division of Hematology, GATA, Etlik, Ankara, Turkey

Published online in Wiley InterScience (www.interscience.wiley.com). DOI: 10.1002/ajh.20344

\section{References}

1. Haas RL, Poortmans P, de Jong D, et al. High response rates and lasting remissions after low-dose involved field radiotherapy in indolent lymphomas. J Clin Oncol 2003;21:2474-2480.

2. Girinsky T, Guillot-Vals D, Koscielny S, et al. A high and sustained response rate in refractory or relapsing low-grade lymphoma masses after low-dose radiation: analysis of predictive parameters of response to treatment. Int J Radiat Oncol Biol Phys 2001;51:148-155.

3. Ganem G, Lambin P, Socie G, et al. Potential role for low-dose limited-field radiation therapy $(2 \times 2$ Grays $)$ in advanced low-grade non-Hodgkin's lymphomas. Hematol Oncol 1994;12:1-8.

4. Sawyer EJ, Timothy AR. Low-dose palliative radiotherapy in low grade nonHodgkin's lymphoma. Radiother Oncol 1997;42:49-51.

5. Johannsson J, Specht L, Mejer J, Jensen BA. Phase II study of palliative low-dose local radiotherapy in disseminated indolent non-Hodgkin's lymphoma and chronic lymphocytic leukemia. Int J Radiat Oncol Biol Phys 2002;54(5):1466-1470.

\section{Rituximab for TTP}

To the Editor: We agree with Ahmad et al. [1] that rituximab is a promising treatment option for patients with refractory TTP due to acquired deficiency of ADAMTS13 metalloproteinase activity. However, we would like to point out that the patients in this report, as well as in previously reported cases [2,3], have been treated with rituximab only after prolonged plasmapheresis and trials of other agents, including vincristine and cyclophosphamide. We feel that rituximab therapy should be considered earlier in the course of the disease, particularly in women of childbearing age who wish to avoid chemotherapeutic agents that could lead to infertility. Here we report our success with use of rituximab therapy in a young woman with refractory TTP shortly after diagnosis. 


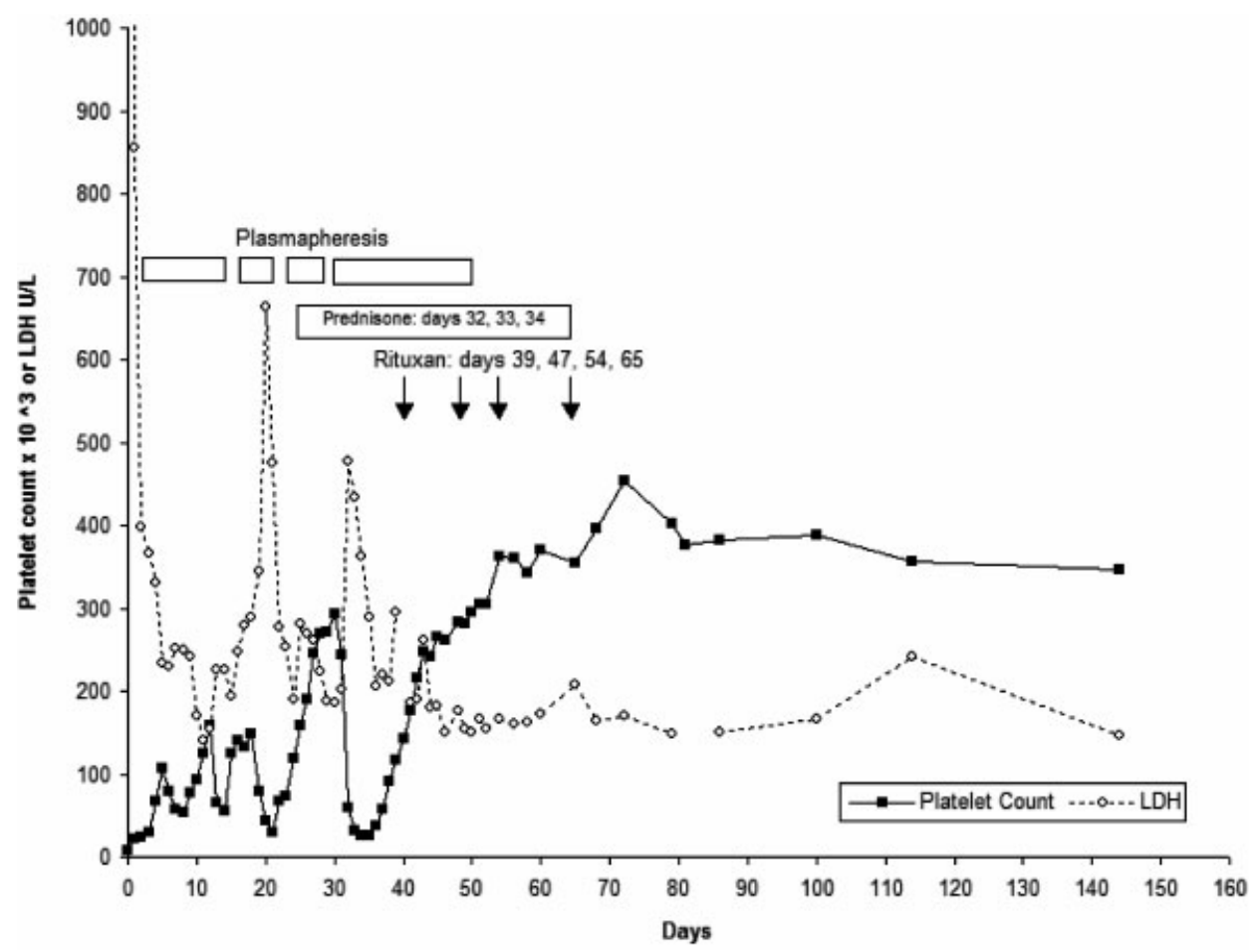

Fig 1. Response of platelet count and LDH to rituximab therapy in 21 year-old woman with refractory TTP. Therapeutic plasma exchange was performed on hospital days $0-11,13-17,20-28,32-49$. Each time that plasmapheresis was discontinued, the platelet count dropped and the LDH rose. Prednisone IV was given on days $32-34$, and rituximab $340 \mathrm{mg} / \mathrm{m}^{2}$ IV was given on days $39,49,54,65$ with sustained normalization of the platelet count and LDH.

A 21-year-old obese woman presented to our emergency room complaining of headache, fever, chills, and confusion. She was diagnosed with TTP based on the presence of thrombocytopenia and microangiopathic hemolytic anemia on peripheral blood smear and was found to have a severe deficiency of ADAMTS13 activity $(<4 \%)$ due to the presence of an inhibitor, with 4.0 inhibitor units detected (normal $<0.4$ inhibitor unit). The patient was treated with daily therapeutic plasma exchange. On three occasions (days 12, 18, and 29 after diagnosis), plasma exchange was discontinued, and each time she experienced a rapid drop in her platelet count and an elevation in her LDH (Fig. 1). Of note, the patient's hospital course was complicated by development of acute cholecystitis requiring a laparoscopic cholecystectomy as well as a central venous catheter infection requiring antibiotic therapy. She was treated with intravenous prednisone, $1 \mathrm{~g}$ daily, on days 32, 33, and 34 after diagnosis and was given rituximab, $340 \mathrm{mg} / \mathrm{m}^{2}$, on days $39,47,54$, and 60 . Daily plasma exchange was discontinued on day 49 . The patient is now 150 days from her diagnosis, with no evidence of relapse.

Based on the favorable outcome observed in our patient and the minimal adverse reactions observed with the use of rituximab to date, we support initiation of rituximab therapy in patients who do not respond to 3-4 weeks of plasma exchange. We believe that earlier use of rituximab could allow patients to avoid more harmful medications, such as vincristine and cyclophosphamide, as well as complications of prolonged hospitalization and plasmapheresis. Several reports to date have documented successful pregnancies in patients who have recovered from TTP [4,5]; for this reason, it seems particularly important to avoid the use of medications that could lead to infertility in women of childbearing age.

Sarah M. ScOtT

ZBignieW M. SZCZEPIORKOWSK

Dartmouth-Hitchcock Medical Center, Lebanon, New Hampshire Published online in Wiley InterScience (www.interscience. wiley.com). DOI: 10.1002/ajh.20364

\section{REFERENCES}

1. Ahmad A, Aggarwal A, Sharma A, et al. Rituximab for treatment of refractory/ relapsing thrombotic thrombocytopenic purpura. Am J Hematol 2004;77:171-176.

2. Gutterman L, Kloster B, Tsai H-M. Rituximab therapy for refractory thrombotic thrombocytopenic purpura. Blood Cells Mol Dis 2002;28:385-391.

3. Yomtovian R, Niklinski W, Silver B, et al. Rituximab for chronic recurring thrombotic thrombocytopenic purpura: a case report and review of the literature. $\mathrm{Br} \mathrm{J}$ Haematol 2004;124:787-795

4. Vesely S, Li X, McMinn JR, et al. Pregnancy outcomes after recovery from thrombotic thrombocytopenic purpura-hemolytic uremic syndrome. Transfusion 2004; 44(8):1149.

5. Ducloy-Bouthors AS, Caron C, Subtil D, et al. Thrombotic thrombocytopenic purpura: medical and biological monitoring of six pregnancies. Eur J Obstet Gynecol Reprod Biol 2003;111(2):146-152.

\section{Management of a Full-Term Infant With Hemolytic Disease of the Newborn Due to an Anti-Rh17 Antibody in a Mother with $\mathrm{D}^{--}$Phenotype}

To the Editor: Pregnant mothers with the $\mathrm{D}^{--}$phenotype can produce anti-Rh17 (anti- $\mathrm{Hr}_{\mathrm{O}}$ ) antibody, which may cause fatal hemolytic anemia in the newborn [1,2]. There have been three cases of successful prenatal management of an infant with this condition $[3,4,5]$. We report the fourth case of management of this rare disorder in a woman who exhibited antiRh17, an antibody which arises in $\mathrm{D}^{--}$individuals exposed to $\mathrm{Rh} 17$, a high incidence erythrocyte antigen, by prior transfusion or pregnancy.

The mother is a 30-year-old gravida 6, para 2032. Previous deliveries were uncomplicated. She had one spontaneous miscarriage and two elective 
terminations, after her successful deliveries. All past medical history was unremarkable. Her blood type is $\mathrm{O}$, Rh-positive, with a positive antibody screen and negative direct antiglobulin test.

Maternal phenotyping showed the patient to be negative for Rh17 (by two examples of anti-Rh17) as well as negative for the C, c, E, and e antigens. The antibody was identified using albumin indirect antiglobulin test (IAT), polyethylene glycol IAT, and papain IAT. No reactivity was seen against four different $\mathrm{D}^{--}$erythrocytes. An anti-Rh17 antibody was present in a 1:128 tube titer (critical value 1:16). One unit of autogeneic blood was donated near term, tested and found to be negative for all required markers of transfusion-transmitted diseases, and stored as frozen red blood cells.

At 36 and 4/7 weeks' gestation, the mother delivered a 3,065 g female infant vaginally. Maternal hematocrit was $28 \%$ with an anti-Rh17 tube titer of 1:256.

The infant's physical exam was significant for jaundice. Admission hemoglobin was $8.6 \mathrm{~g} / \mathrm{dL}$ with a reticulocyte count of $48 \%$. The infant's blood type was $\mathrm{O}$, Rh-positive $\mathrm{C}^{+} \mathrm{c}^{-} \mathrm{E}^{-} \mathrm{e}^{+}$, and her direct antiglobulin test was $3^{+}$positive with $\mathrm{IgG}$-specific antiglobulin reagent. The crossmatches of the mother's plasma against allogeneic rr reconstituted red blood cells were $3^{+}$incompatible.

The infant received one $45 \mathrm{~mL}(15 \mathrm{~mL} / \mathrm{kg})$ transfusion of maternal packed red blood cells. Maternal blood was used initially to provide red blood cell volume and diminish hemolysis, as maternal blood type was negative for Rh17 and thus presented the lowest burden of antigenic substrate for anti-Rh17 antibody, forestalling further jaundice and kernicterus.

Bilirubin increased to $21.3 \mathrm{mg} / \mathrm{dL}$ by 12 hours of life. Treatment with intravenous immunoglobulin was initiated to provide increased antibody levels and occupy binding sites on the surface of the red blood cell membrane of the infant, rendering it less vulnerable to hemolysis by maternally derived antibody to Rh17. The infant also underwent three double-volume exchange transfusions: the first with reconstituted, compatible, irradiated, deglycerolized maternal red blood cells. This, again, provided the best source of red blood cell volume with no red cell antigenic substrate for anti-Rh17. Remaining exchange transfusions were performed with allogeneic rr O reconstituted blood, which is incompatible, given the infant's antibody.

At $30 \mathrm{hr}$ after birth, the bilirubin level decreased to $13.7 \mathrm{mg} / \mathrm{dL}$. The infant was discharged seven days after birth with a bilirubin of $5.7 \mathrm{mg} / \mathrm{dL}$. At age four months, the child has met all appropriate developmental milestones and is in good health.

\section{Shetal I. Shah Martha Caprio 1 Robert Strauss ${ }^{2}$ NAOMı Moskowitz}

${ }^{1}$ Department of Pediatrics, Division of Neonatal Medicine, New York University Medical Center Tisch Hospital/Bellevue Medical Center, New York, New York

${ }^{2}$ Department of Pathology, New York University School of Medicine/ Bellevue Medical Center, New York, New York

${ }^{3}$ Department of Pediatrics, Division of Hematology/Oncology, New York University Medical Center Tisch Hospital/Bellevue Medical Center, New York, New York

Published online in Wiley InterScience (www.interscience. wiley.com). DOI: 10.1002/ajh.20370

\section{REFERENCES}

1. Badakere $\mathrm{S}$, Bhatia $\mathrm{H}$. Haemolytic disease of the newborn in a $\mathrm{D}^{--} / \mathrm{D}^{--}$Indian woman. Vox Sang 1973;24:280-282.

2. DeTorregrosa M, Rullan M, Cecile C, et al. Severe erythroblastosis in primigravida associated with absence of Rh chromosomes. Am J Obstet Gynecol 1961;82:13751378 .

3. Deitenbeck R, Tutchec B, Crombach G, et al. Successful management of pregnancy and hemolytic disease of the newborn due to anti- $\mathrm{Hr}_{\mathrm{O}}$ in a woman of $\mathrm{D}^{--}$phenotype. Transfusion 1999;39:1150-1151.
4. Diao Y, SongN, Guan Z, et al. A case of hemolytic disease of the newborn caused by anti-Hr $\mathrm{H}_{\mathrm{O}}$ and anti-e. Proc Chin Acad Med Sci 1990;(1):58-60.

5. Denomme GA, Ryan G, Seaward PG, Kelly EN, Fernandes BJ. Maternal ABOmismatched blood for intrauterine transfusion of severe hemolytic disease of the newborn due to anti-Rh17. Transfusion 2004;44:1357-1360.

\section{Acute Megakaryoblastic Leukemia in a Patient Receiving HAART}

To the Editor: B-cell lineage-derived intermediate and high-grade malignant lymphomas are a well-recognized complication of HIV infection, but acute myelogenous leukemia and myeloproliferative diseases are rare in HIV patients. This is the first report of M7 in an HIV patient.

A 44-year-old male, intravenous drug user, HIV-infected since 1988, with previous multiple AIDS-related illnesses, presented with fever and dyspnea. In 1997, he had started highly active anti-retroviral therapy (HAART), and he had been exposed irregularly to most anti-retroviral drugs due to poor compliance. CD4 cell count remains below $200 \times 10^{6}$ cells/1, but he had achieved virologic suppression for the previous 3 months. On physical examination at admission, he showed hepatosplenomegaly and laterocervical lymphoadenopathy. Laboratory values revealed white blood count $3.2 \times 10^{9}$ cells/L, platelets $208 \times$ $10^{9}$ cells/L, hematocrit $31.5 \%$, mean corpuscular volume $92.5 \mathrm{fL}$, elevated serum lactate dehydrogenase, hypocalcemia, hypoalbuminemia, and hypokalemia. He had Pneumocystis carinii pneumonia, but persisting febrile and neutropenic status prompted a bone marrow biopsy, which showed bone

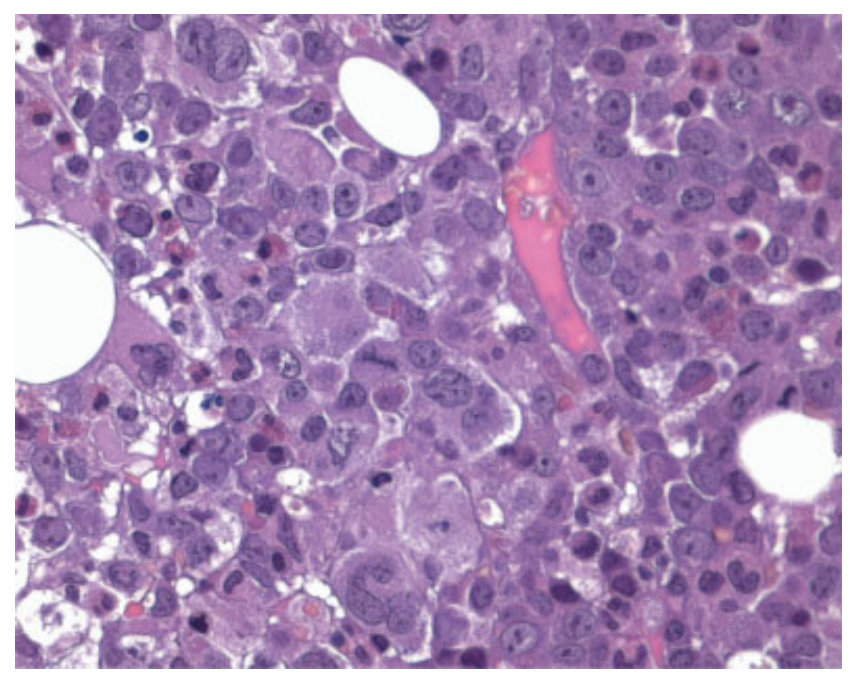

Fig. 1. Bone marrow trephine biopsy. The bone marrow cavities are hypercellular and are populated by blast cells and dysplastic megakaryocytes (original magnification 400x, H\&E). Moreover, bone marrow sections were immunostained for CD31/PECAM (platelet endothelial cell adhesion molecule). Some large dysplastic megakaryocytes are stained in the cytoplasm; other large cells with similar morphology were stained only at the membrane level. The diagnosis of M7 was based on the presence of $\mathrm{CD} 31^{+}$blast cells; these latter were negative for myeloperoxidase, glycophorin, CD68, CD20, and CD3. The diagnosis was confirmed at autopsy, when multiorgan involvement by megakaryocytes was demonstrated. The majority of blast cells and of dysplastic megakaryocytes were negative for vWF; however, isolated cells were positive. [Color figure can be viewed in the online issue, which is available at www.interscience.wiley.com.] 
marrow cavities markedly hypercellular and occupied by a polymorphous cell population of $\mathrm{CD} 31^{+} / \mathrm{CD} 1^{+} / \mathrm{vWF}^{+}$mature megakaryocytes, $\mathrm{CD} 31^{+}$ dysplastic megakaryocytes, and large nests of $\mathrm{CD} 31^{+}$blast cells associated with fibrosis (Fig. 1). Blast cells were negative for CD20, glycophorin, MPO, and CD68. A diagnosis of M7 was made. He died from progressive infection. An autopsy revealed multiple leukemia involvement of tissues, including the bone marrow, spleen, hepatic sinusoids, and mediastinal lymph nodes with accumulation of $\mathrm{CD}_{3} 1^{+}$large cells, most of which had typical megakaryocyte morphology.

An association between HIV infection and AML has not been demonstrated by epidemiological studies across various tumor registries [1]. However, some authors have reported a 2-fold higher incidence of AML, especially type M4/5, in HIV patients compared to the general population [2]. Moreover, AML shows a high incidence in two disorders associated with chronic T-cell abnormalities [3].

The increased survival of HIV patients, HAART-related, has been associated with an increased development of more malignancies [4]. Although improvement in HIV-associated hematological disorders after HAART administration, has been described, the repercussion of HAART on chronic thrombocytopenia is not clear [5], and prolonged antiretroviral treatment could lead to development of rare megakaryocytic cell-line disorders.

\section{Dora LaRussa ${ }^{1}$ SusANNA GriseTtI Emanuela PilozzI Patrizio Concorsi ${ }^{3}$ Roberto PISA ${ }^{3}$ LUIGI RuCO \\ Andrea Antinori}

${ }^{1}$ Dipartimento Clinico, Istituto Nazionale per le Malattie Infettive Lazzaro Spallanzani IRCCS, Roma, Italy

${ }^{2}$ Dipartimento di Diagnostica di Laboratorio e Patologia, Ospedale Sant'Andrea, II Facoltà di Medicina e Chirurgia, Università "La Sapienza," Roma, Italy

${ }^{3}$ Servizio di Anatomia Patologica, Azienda Ospedaliera S. CamilloForlanini, Roma, Italy

Published online in Wiley InterScience (www.interscience.wiley.com). DOI: 10.1002/ajh.20377

\section{REFERences}

1. Frisch M, Biggar RJ, Engels EA, Goedert JJ. AIDS-Cancer Match Registry Study Group. Association of cancer with AIDS-related immunosuppression in adults. JAMA 2001;285(13):1736-1745

2. Sutton L, Guenel P, Tanguy ML, et al. French Study Group on Acute Myeloid Leukaemia in HIV-Infected Patients. Acute myeloid leukaemia in human immunodeficiency virus-infected adults: epidemiology, treatment feasibility and outcome. $\mathrm{Br}$ J Haematol 2001;112(4):900-908.

3. Aboulafia DM, Meneses M, Ginsberg S, Siegel MS, Howard WW, Dezube BJ Acute myeloid leukemia in patients infected with HIV-1. AIDS 2002;16:865-876.

4. Dal Maso L, Franceschi S, Polesel J, et al. Cancer and AIDS Registry Linkage Study. Risk of cancer in persons with AIDS in Italy, 1985-1998. Br J Cancer 2003;89(1):94-100

5. Miguez MJ, Burbano X, Archer H, Shor-Posner G. Limited impact of highly active antiretroviral therapy in thrombocytopenia. J Acquir Immune Defic Syndr 2002;30(2):260-261

\section{Acute Transient Leukopenia as a Sign of TRALI}

To the Editor: Transfusion-related acute lung injury (TRALI) is characterized by acute respiratory distress, hypoxemia, hypotension, fever, and widespread pulmonary infiltrates [1]. Without a gold standard, the diagnosis is based on a high index of suspicion based on a constellation of signs and symptoms. We report two patients with TRALI accompanied by a precipitous drop in the leukocyte count. We propose that leukopenia may be a tool to help diagnose this condition.

\section{Case Report 1}

A 38-year-old female with thrombotic thrombocytopenic purpura (TTP) undergoing plasma exchange, suddenly complained of "hot flashes" and chest tightness, which quickly progressed to respiratory distress, headache, chills, nausea, and hypoxemia. After symptomatic treatment, she slowly improved. A complete blood cell count (CBC) collected during the episode revealed a white cell count of $3.2 \times 10^{9} / \mathrm{L}$, compared to $11 \times 10^{9} / \mathrm{L}$ from $6 \mathrm{hr}$ earlier. A chest radiograph showed new bilateral pulmonary opacities; however, the patient did not require intubation. Ten hours later, her white blood cell count was back at $11.2 \times 10^{9} / \mathrm{L}$. She recovered well, and her chest was clear 6 days later.

\section{Case Report 2}

A 78-year-old male was admitted with multiple fractures following a motor vehicle accident. On the second hospital day, he was intubated prior to surgery and maintained on minimal ventilator settings. In order to correct a prolonged prothrombin time, he was transfused fresh frozen plasma (FFP). Within minutes of receiving the fourth unit, he developed significant respiratory distress with tachypnea, hypoxemia, elevated peak pressures, and fever $\left(38.1^{\circ} \mathrm{C}\right)$. A chest radiograph revealed whitening of the lungs, ventilator requirements increased significantly, and his $\mathrm{O}_{2}$ saturations remained in the low $80 \%$ for $24-36 \mathrm{hr}$. A presumptive diagnosis of TRALI was made, and a CBC collected $2 \mathrm{hr}$ after the symptoms started showed severe leukopenia $(0.7 \times$ $10^{9} / \mathrm{L}$ ) compared with a white blood cell count of $8.8 \times 10^{9} / \mathrm{L}$ prior to the transfusion. Six hours later, he was still leukopenic at $3.2 \times 10^{9} / \mathrm{L}$. However, his white count progressively increased over the ensuing hours. He was treated with hydration and prednisolone and maintained on mechanical ventilatory support for several days.

The implicated FFP units in both cases had strong evidence of HLA class I and II antibodies (Flow PRA, One Lambda, Canoga Park, CA), strengthening the clinical diagnosis of TRALI. Of note, both patients experienced mainly neutropenia and monocytopenia with corresponding increases in the percentages of bands and lymphocytes following the acute episode. Leukopenia during TRALI is consistent with massive agglutination of leukocytes in the pulmonary microcirculation due to HLA-specific antibodies in the donor plasma [2,3]. Although TRALI-associated leukopenia has been described before $[4,5]$, it is not widely recognized as a potentially useful diagnostic clue. We propose that a complete blood cell count be ordered in all suspicious cases. If leukopenia is evident, it will help point to the diagnosis of TRALI, since no other acute transfusion reaction is accompanied by leukopenia. Furthermore, TRALI should be included in the differential diagnosis of unexplained and sudden leukopenia in transfusion recipients.

Marisa B. MARQues ${ }^{1}$ HANDE H. TunCER ${ }^{1,3}$ Stephen G. Divers ${ }^{2,4}$ Allyson C. BaKer ${ }^{1}$

D. Keith Harrison ${ }^{1}$

${ }^{1}$ Department of Pathology, University of Alabama at Birmingham, Birmingham, Alabama

${ }^{2}$ Department of Medicine, University of Alabama at Birmingham, Birmingham, Alabama

${ }^{3}$ Department of Medicine, Tufts-New England Medical Center, Boston,

Massachusetts, and

${ }^{4}$ Genesis Cancer Center, Hot Springs, Arkansas

Published online in Wiley InterScience (www.interscience.wiley.com).

DOI: 10.1002/ajh.20378 


\section{REFERENCES}

1. Popovsky MA, Moore SB. Diagnostic and pathogenetic considerations in transfusion-related acute lung injury. Transfusion 1985;25:573-577.

2. Kopko PM, Popovsky MA, MacKenzie MR, Paglieroni TG, Muto KN, Holland PV. HLA class II antibodies in transfusion-related acute lung injury. Transfusion 2001;41:1244-1248.

3. Kao GS, Wood IG, Dorfman DM, Milford EL, Benjamin RJ. Investigations into the role of anti-HLA class II antibodies in TRALI. Transfusion 2003;43:185-191.

4. Wallis JP, Lubenko A, Wells AW, Chapman CE. Single hospital experience of TRALI. Transfusion 2003;43(8):1053-1059.

5. Yomtovian R, Kline W, Press C, et al. Severe pulmonary hypersensitivity associated with passive transfusion of a neutrophil-specific antibody. Lancet 1984;1:244-246.

\section{Gemcitabine-Induced Radiation Recall Dermatitis in a Patient With Resistant Hodgkin Lymphoma}

To the Editor: Radiation recall refers to inflammatory reactions throughout a previously irradiated area, precipitated by the administration of certain drugs, usually intravenous cytotoxics [1]. The time period from radiation exposure to trigger-drug administration may range from several days to years [1]. According to a literature search using PubMed, only 13 cases of radiation recall induced by gemcitabine during the treatment of different cancers have been reported [1-4]. Comparison of radiation recall attributed to gemcitabine with cases triggered by anthracyclines and taxanes [4] showed several differences. Namely, the interval from the completion of radiation therapy to the initiation of chemotherapy is less for gemcitabine (median time of 56 days for gemcitabine, compared with 218 days for the taxanes and 646 days for doxorubicin). The majority of radiation-recall reactions attributed to gemcitabine are reported to affect internal tissue or organs. In contrast, other common agents, for the most part, trigger cutaneous inflammation.

The main clinical features of radiation-recall dermatitis (RRD) are erythema, with or without desquamation, edema, urticaria-like lesions, vesiculation, necrosis, ulceration, and hemorrhage. Patients usually complain of pruritus or pain. All clinical signs tend to resolve without any specific treatment in several weeks. Steroids, systemic or topical, as well as antihistamines control only pruritus and/or pain. RRD occurs at the first exposure to a particular trigger-drug. Rechallenge with the same drug may provoke another recall reaction. Usually, recurrence of RRD presents with milder clinical signs than with the first time [1].

We report herein a first case of RRD from gemcitabine employed in the treatment of Hodgkin lymphoma.

A 32-year-old female patient with stage IIB Hodgkin lymphoma was initially treated with the MOPP chemotherapy protocol and subsequent supradiaphragmal "mantle field" radiotherapy (total dose of $60 \mathrm{~Gy}$ ). Her lymphoma resolved, but in the next several months she developed a subcutaneous fibrous proliferation, which caused impaired lymphatic drainage in the irradiated field. Six months later, she relapsed. Her second hematological remission was achieved with the ABVD protocol. Two years later, she relapsed again. After failure of Dexa-BEAM, the gemcitabine-dexamethasone protocol was introduced (gemcitabine 1250 $\mathrm{mg} / \mathrm{m}^{2}$ on days 1,8 , and 15 i.v., dexamethasone $8 \mathrm{mg}$ on days $1,2,8,9$, 15 , and 16 orally). Within 2 days after the first administration of gemcitabine, she developed a painful, warm, erysipelas-like erythema, with a fever (up to $39^{\circ} \mathrm{C}$ ), confined to the area of irradiation (Fig. 1). Genuine erysipelas was excluded by laboratory tests (erythrocyte sedimentation rate, ASO titer) and clinical observation. The skin reaction had faded out 10 days after, without specific treatment, but occurred again after each of the subsequent administrations of gemcitabine (six times in total), but with only mild clinical symptoms, erythema, and pruritus.
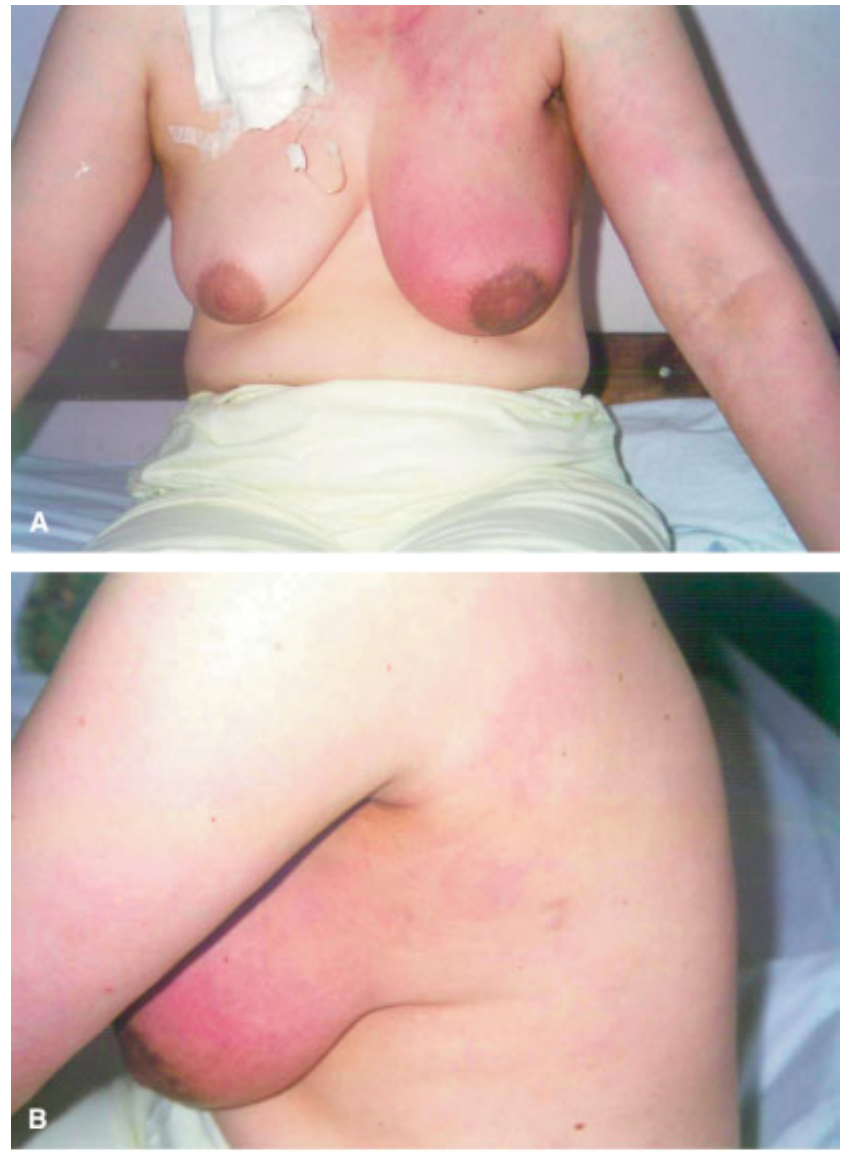

Fig. 1. An erysipelas-like erythema restricted to the area of irradiation: enlargement of the left arm and mamma due to impaired lymphatic drainage (A); and not expanded to the back $(B)$. [Color figure can be viewed in the online issue, which is available at www.interscience.wiley.com.]

Dragomir Marisavljević BILJANA Ristić Jelena Hajder

Medical Training Centre "Beanijska kosa," Belgrade, Serbia and Montenegro

Published online in Wiley InterScience (www.interscience.wiley.com). DOI: 10.1002/ajh.20379

\section{References}

1. Camidge R, Price A. Characterizing the phenomenon of radiation recall dermatitis. Radiother Oncol 2001;59:237-245.

2. Brandes A, Reichmann U, Plasswilm L, Bamberg M. Time and dose limiting erysipeloid rash confined to areas of lymphedema following treatment with gemcitabine - a report of three cases. Anticancer Drugs 2000;11:15-17.

3. Schwartz BM, Khuntia D, Kennedy AW, Markman M. Gemcitabine-induced radiation recall dermatitis following whole pelvic radiation therapy. Gynecol Oncol 2003;91(2):421-422.

4. Friedlander PA, Bansal R, Schwartz L, Wagman R, Posner J, Kemeny N. Gemcitabine-related radiation recall preferentially involves internal tissue and organs. Cancer 2004;100(9):1793-1799. 


\section{Refractory Megaloblastic Anemia in a Patient With AIDS: Response to Danazol}

To the Editor: Megaloblastic erythropoiesis in patients with AIDS can be secondary to trimethoprim-sulfamethoxazole or pyrimethamine therapy $[1,2]$. It can also be a component of AIDS-related myelodysplasia [3]. I describe a patient with AIDS who developed severe refractory megaloblastic anemia that responded well to danazol therapy, a finding that has not been reported previously.

A 34-year-old man was begun on treatment with zidovudine, lamivudine, and efavirenz for asymptomatic HIV infection. His pretreatment blood counts were normal, the $\mathrm{CD} 4^{+} \mathrm{T}$-lymphocyte count was $108 \mathrm{~mm}^{3}$, and HIV RNA was at 49,051 copies $/ \mathrm{mL}$. Three months later, he complained of fatigue and weakness. His $\mathrm{Hb}$ was $5.9 \mathrm{~g} / \mathrm{dL}$, reticulocytes $0.1 \%$, MCV $93 \mathrm{fL}$, total leukocytes $1.1 \times 10^{9} / \mathrm{L}$, and platelets $222 \times 10^{9} / \mathrm{L}$. The blood smear examination showed marked anisopoikilocytosis and macro-ovalocytes. The serum vitamin $B_{12}$ level was $542 \mathrm{pg} / \mathrm{mL}$, folic acid $>20 \mathrm{ng} / \mathrm{mL}$, and serum erythropoietin $541 \mathrm{mU} / \mathrm{mL}$. The bone marrow aspirate showed a hypercellular marrow, normal megakaryocytes, florid megaloblastic erythropoiesis, and occasional giant bands. The serum and bone marrow aspirate were negative for parvovirus B19 DNA by PCR.

Zidovudine therapy was stopped, and he was begun on treatment with stavudine, erythropoietin, and G-CSF. Over the subsequent 6 months, he received a total of 17 units of packed erythrocyte transfusions; he had been treated with injection erythropoietin (40,000 units daily, 5 days/week) and G-CSF (300 $\mu \mathrm{g}, 3$ times/week) for the 2 months prior to his referral to the Core Center.

On evaluation at the Core Center, his examination showed normal findings except for a palpable spleen tip. His hemoglobin was $6.8 \mathrm{~g} / \mathrm{dL}$, reticulocytes $4 \%$, MCV $133 \mathrm{fL}$, leukocytes $5.1 \times 10^{9} / \mathrm{L}$, and platelets $235 \times 10^{9} / \mathrm{L}$. The direct antiglobulin test and test for cold agglutinins were negative. His $\mathrm{CD}^{+}{ }^{+}$T-lymphocyte count was $222 \mathrm{~mm}^{3}$ and HIV RNA was at 256 copies/ $\mathrm{mL}$. A bone marrow aspirate performed after 10 days of therapy with $1 \mathrm{mg}$ of parenteral vitamin $B_{12}$ and $1 \mathrm{mg}$ of folic acid orally daily showed no change in marrow morphology as compared to the previous marrow examination; karyotypic analysis showed normal findings.

He was begun on treatment with danazol ( $200 \mathrm{mg}, 3$ times/day), and the erythropoietin and G-CSF doses were gradually tapered. Six months after the start of danazol therapy, his hemoglobin was $17.3 \mathrm{~g} / \mathrm{dL}, \mathrm{MCV} 127 \mathrm{fL}$, total leukocytes $10.5 \times 10^{9} / \mathrm{L}$, and platelets $197 \times 10^{9} / \mathrm{L}$. The spleen was not palpable. Treatment with erythropoietin and G-CSF was stopped. Two months later, his hemoglobin was $15.5 \mathrm{~g} / \mathrm{dL}, \mathrm{MCV} 127 \mathrm{fL}$, total leukocytes $6.6 \times 10^{9}$ $\mathrm{L}$, and platelets $280 \times 10^{9} / \mathrm{L}$. A repeat bone marrow aspirate showed hypercellular marrow with normal megakaryocytes, normal myelopoiesis, and a mild degree of nuclear-cytoplasmic asynchrony in the erythroid cells.

Whether the megaloblastic erythropoiesis in our patient was due to an immune-mediated block in vitamin $\mathrm{B}_{12}$ and/or folate metabolism is unknown. The results of danazol therapy in myelodysplastic syndromes have been conflicting [4,5]. Because of lack of serious side effects and its immunomodulatory effects, danazol use should be considered in selected patients with AIDS-related myelodysplasia.

Prasad R. Koduri

Division of Hematology-Oncology, Cook County Hospital, The Core Center for the Diagnosis, Research and Care of Infectious Diseases, Chicago, Illinois

Published online in Wiley InterScience (www.interscience.wiley.com). DOI: 10.1002/ajh.20412

\section{REFERENCES}

1. Shami PJ, Crews J. Megaloblastic cytopenia in an AIDS patient treated with trimethoprim-sulfamethoxazole. N C Med J 1995;56:602-604.

2. Chute JP, Decker CF, Cotelingam J. Severe megaloblastic anemia complicating pyrimethamine therapy. Ann Intern Med 1995;122:884-885.

3. Karcher DS, Frost AR. The bone marrow in human immunodeficiency virus (HIV)related disease. Am J Clin Pathol 1991;95:63-71.
4. Aviles A, Rubio ME, Gomez J, Medina ML, Gonzales-Llaven J. Randomized study of danazol vs. placebo in myelodysplastic syndromes. Arch Invest Med (Mex) 1989;20:183-188.

5. Chabannon C, Molina L, Pegourie-Bandelier B, Bost M, Leger J, Hollard D. A review of 76 patients with myelodysplastic syndromes treated with danazol. Cancer 1994; $73: 3073-3080$

\section{Treatment of Refractory Immune Cytopenias in the $21^{\text {st }}$ Century-How Safe Is Rituximab?}

To the Editor: Dr. Qazilbash et al. [1] describe the clinical course a 20-yearold young woman who developed cold antibody immune hemolytic anemia (CIHA) following a T-cell depleted, matched, unrelated marrow transplantation for chronic myelogenous leukemia. The CIHA was unresponsive to steroids, IVIG, and plasmapheresis. Rituximab was then given, and shortly thereafter, she developed fulminant hepatopathy to which she succumbed. Serologic and molecular studies failed to identify a viral etiology. A second case describes a 21-year-old with Evans syndrome and large B-cell lymphoma who died of fulminant hepatitis B after 3 courses of CHOP plus rituximab [2]. Serologic studies showed that the patient was unable to mount an antibody response to hepatitis B. The Evans syndrome, diagnosed at age 5 years, was managed with steroids and IVIG and had been in clinical remission for over 6 years before he developed the lymphoma.

There are at least six other published cases of fatalities following rituximab usage: one post-renal transplant patient was treated for PTLD, and 5 others, all adults (age 53-73 years, 4 of whom were older than 60 years), were treated for large-cell or follicular lymphoma; four of the deaths were associated with a progressive hepatitis, one with generalized cytomegalovirus infection, and one with disseminated varicella. Thus far, no deaths have been reported in children receiving rituximab for immune cytopenias, but there is one report of a near-fatal anaphylactic reaction [3]. Case reports of activation of parvovirus B19 and severe pure red-cell aplasia following Rituximab therapy have been published [4].

A likely common thread is an underlying immune deficiency. In the case described by Qazilbash et al. [1], the patient underwent an T-cell depleted, unrelated marrow transplant and was on tacrolimus when she developed CIHA. Suzan et al. described a patient undergoing renal transplant at age 64 years who was still on cyclosporine when PTLD was diagnosed 10 years later and developed fatal cytomegalovirus infection post rituximab [5]. The case described by Özgönenel et al. was that of a 21-year-old man with Evans syndrome and was known to have chronic lymphadenopathy [2]. Such patients have been previously suspected to have an underlying immune disorder, now identified as autoimmune lymphoproliferative syndrome characterized by the presence of increased numbers of double-negative T cells (CD3-positive and CD4/CD8-negative) and abnormal apoptosis due to defects of Fas/Fas ligand interactions. $\mathrm{Ng}$ et al. described a 50-year-old female, diagnosed with proBlymphocytic leukemia, who was treated with a regimen that included fludarabine for 6 courses and then rituximab weekly $4 \times$ for consolidation. It is likely that, in this case, the T-cell function was depressed from prior exposure to fludarabine and the loss of B-cell function post-rituximab was additive. Other fatal infections occurred in individuals 65 years or older, in whom age-associated loss in immune competency may have played a critical role.

These cases suggest that rituximab should be used with great caution for treatment of immunocytopenias or lymphoproliferative disorders in patients with an underlying immune dysfunction, either de novo or treatment-related.

YadDANAPUd RAVINDRANATH

Georgie Ginopolis Chair for Pediatric Cancer and Hematology, Wayne State University School of Medicine, Children's Hospital of Michigan, Detroit, Michigan

Published online in Wiley InterScience (www.interscience.wiley.com). DOI: 10.1002/ajh.20464 


\section{References}

1. Qazilbash M. Rituximab-induced acute liver failure after an allogeneic transplantation for chronic myeloid leukemia. Am J Hematol 2005 (in press).

2. Özgönenel BS, et al. Fulminant hepatitis b following rituximab therapy in a patient with Evans syndrome and large B-cell lymphoma. Am J Hematol (submitted).
3. Bader-Meunier B, Gabolde M, Casadevall N, Seguin G, Tchernia G. Life-threatening complication of Rituximab in a child. Haematologica 2002;87:ECR45.

4. Sharma VR, Fleming DR, Slone SP. Pure red cell aplasia due to parvovirus B19 in a patient treated with rituximab. Blood 2000;96:1184-1186.

5. Suzan F, Ammor M, Ribrag V. Fatal reactivation of cytomegalovirus infection after use of rituximab for a post-transplantation lymphoproliferative disorder. $\mathrm{N}$ Engl $\mathbf{J}$ Med 2001;345:1000. 